\title{
THE REVIVAL OF EMOTIONAL MEMORIES AND ITS THERAPEUTIC VALUE. (I ${ }^{1}$
}

BY WILLIAM BROWN.

The subject of this discussion is: "The revival of emotional memories and its therapeutic value." It is an important question, because the method of bringing up earlier memories and working them off has become more and more the approved method of treating the psychoneuroses. What we want to know is the 'rationale' of this methodthe kind of hypothesis that would best harmonize it with the general principles of Psychology.

We might begin with the facts. It has been found again and again in the case of shell-shock patients, especially those seen in the field, that they suffer from loss of memory of the incidents immediately following upon the shell-shock, and that, if these memories are brought back again afterwards with emotional vividness--hallucinatory vividness, I might say - the other symptoms which they were showing tend to disappear. The degree of the recovery varies from case to case, but one does notice, in many cases, complete recovery. All cases of loss of voice, for example, seem curable by this means, without exception. In the case of functional paralysis movement in the paralysed limbs occurs, but not necessarily complete recovery of muscular power at first ${ }^{2}$.

The essential thing seems to be the revival of the emotion accompanying the memory. This was easily brought about in the case of shellshock soldiers seen in the field shortly after their injury. It was more difficult to produce the emotional revival in patients seen later in England. One patient suffering from functional deaf-mutism, whom I saw in England, recovered all his memories when hypnotised by me on several occasions, but did not regain his voice or hearing until, at last, he woke up at night from a very vivid dream, tumbled out of bed, and both heard and spoke. In the case of deaf-mutes treated in the field such failure never occurred. The explanation seems to be that, in this case, I did not produce the emotional revival with sufficient vividness.

Considered in a rough, popular manner, the facts seem to indicate

1 A contribution to a discuseion at a meeting of the Medical Section of the British Psychological Society on February 18, 1920.

2 Cf. my article, "Treatment of Cases of Shell Shock in an Advanced Neurological Centre," The Lancet, 1918, ח. 197. Also "War Neurosis," Proc. Roy. Soc. Med. 1918, xா. 
that emotion has been pent up in these patients, under strain of attempted self-control, and that liberation of such pent-up emotion (known as 'abreaction') produces a resolution of the functional symptoms. Another obvious factor, of course, is the re-synthesis of the mind of the patient-the amnesia has been abolished, and the patient has once more full sway over his recent memories.

Can we say that the emotion the patient experiences under hypnosis is identical with the emotion that he felt, or began to feel, at the time of the mental shock? An alternative view might be that the circumstances of the original shock are brought so vividly and cognitively to his mind under hypnosis that they again arouse an emotion of fear, but an emotion which is a present emotion, which may be less intense, but quite possibly may be more intense and of different quality from that which he originally experienced, or began to experience. According to the JamesLange theory of emotion this latter explanation would be the more probable one. The adherents of this theory might hold that a complex of visceral and other sensations is aroused at the time of the hypnosis through the mediation of the cognitively-revived experience, and so forms the present emotion. But psychologists find it impossible to accept the James-Lange theory, since an emotional experience is always more than a sum of organic sensations, in that it involves a reference, vague or explicit, towards some object, in the psychological sense of that word. All the evidence quoted from pathology in favour of the theory - from cases of visceral anaesthesia on the one hand and heightened emotionality on the other-equally fails to prove the absence of this subject-object relationship in any single case.

Hypnotic experiments in the revival of early memories of childhood seem to confirm one in the view that the emotional tone of the individual experiences is retained in the mind in the same way in which those experiences themselves are retained, so that, although the mind becomes more and more complex in various ways in course of time, and various experiences, that later on leave their traces in memory, interact, as it were, with one another and produce more complex mental formations, there is at least a continuous thread of actual experience being deposited in memory from moment to moment, like the successive photographic views on a cinematograph ribbon, and these early memories can be revived in the exact form in which they were originally laid down as the mind passed beyond them to new experiences. I will quote one case to illustrate what I mean. In one of my patients I recalled under hypnosis the events of his sixth birthday. He proceeded to live again through the 
exact experience. His face lighted up with joy as he saw the birthday presents that his father and mother had given him. A moment later he commences to weep bitterly, because he remembers that his little sister is very ill upstairs, and that the doctor has just been. A fortnight later, when testing his memory for other early events, I inadvertently suggested once more the revival of those of his sixth birthday, forgetting that I had done so before. He went through exactly the same experiences, his emotion of joy giving place later to the emotion of desperate grief. The two revivals were practically identical. Here it seems as if the two different emotions were integral elements in the successive memories, and that they were certain to come up if the memories were revived in their ideational completeness.

As against facts like these, we find instances where, at one time, an early emotional experience can be revived cognitively in great detail without the accompanying emotion, whereas, on other occasions, the same attempt at revival inevitably re-arouses the emotion as well. We must assume here, either that our cognitive memories form systems of mental dispositions linked up with, but nevertheless relatively independent of, other mental dispositions corresponding to the different primary and secondary emotions, as Dr W. McDougall suggests in Chapter III of his book on Psychology (Home University Library), or else we must assume that the cognitive revival without emotion has simply been incomplete revival, and that, if the revival had been sufficiently detailed, had possessed hallucinatory vividness, the emotion would have been revived simultaneously.

In certain cases of emotional memories one finds, as a matter of experience, that there does seem to be an over-burdening of the memory with emotion, and that this excessive emotion can be worked off by revival, with relief to the patient's mind (p8ycho-catharsis). If the same emotional experience is again aroused later, he no longer shows such excessive emotional reaction.

Freud has likened emotional energy to an electric charge, which can spread over the surface of a body, and can shift from one part to another; emotional energy, in a similar manner, shifting from one memory to another, or gaining physical outlet in emotional reaction, muscular, visceral and vaso-motor.

McDougall's theory of the structure of the mind and his hypothesis of different mental dispositions, of cognitive knowledge on the one hand and the various emotions on the other, give us a different view of the psychological situation. According to his view one can indeed under- 
stand the therapeutic results of sublimation, where emotional dispositions, that have originally found an outlet through association with certain sets of cognitive dispositions, can later on become associated with other cognitive dispositions and function in connection with them to the partial or complete exclusion of the former cognitive dispositions.

As regards the simpler phenomenon of 'abreaction,' I have myself suggested a similar explanation, which I stated as follows: "It seems to me that we have a two-fold dissociation in these cases (shell-shock of hysterical type). In the first place, the shock of the shell explosion has produced a dissociation from the patient's personal consciousness of certain psycho-physical functions together with the memories linked with them immediately after the shock. But a second dissociation has also occurred, viz. that between the psychical (I should have written "psychophysical') and physical counterparts of the emotional reaction of fear. The physical counterpart then persists instead of being evanescent. The first dissociation has to do with the central nervous system, the second has to do with the sympathetic. Revival of emotion with hallucinatory vividness, soon after the original shock, abolishes the second dissociation as well as the first, and so brings the physical manifestation of the emotion again under the sway of the conscious personality.".

But although such associational theories are as far as we can go on the psycho-physiological plane of explanation, psychologically we are forced to recognise the great therapeutic effect produced by the intellect in the analytic review of past memories, especially in the analytic treatment of what have been called 'anxiety states,' where the patient is helped and encouraged to look at past events from a more impersonal point of view, and so to obtain a deeper insight into their mutual relations and intrinsic values. The method, which might be called the method of autognasis, does produce a readjustment of emotional values among the patient's past memories. These memories are all scrutinized from the point of view of the patient's developed personality-or rather of his ideal of personality so far as it becomes revealed in the course of the analysis-and the relative autonomy that some of them had previously enjoyed by virtue of their emotional over-emphasis is withdrawn from them. The progress is one from a state of relative dissociation to a state of mental harmony and unity. The 'abreaction' of excessive emotion here is no merely mechanical process, but is controlled at every step by the principle of relativity and intellectual adjustment.

1 "Hypnosis, Suggestion and Dissociation," Brit. Med. Journ. June 14th, 1918. 